\title{
POSTHUMANISM AND ASSISTIVE TECHNOLOGIES: \\ ON THE SOCIAL INCLUSION/EXCLUSION OF LOW-TECH CYBORGS
}

\section{TECNOLOGIAS ASSISTIVAS E POS-HUMANISMO: SOBRE A INCLUSÃO/EXCLUSÃO SOCIAL DOS CIBORGUES LOW-TECH}

\author{
Elizabeth Kath ${ }^{*}$ \\ Osorio Coelho Guimarães Neto**, ${ }^{* * *}$ \\ Marcelo El Khouri Buzato****
}

\begin{abstract}
In this paper, we elaborate on the consequences of a post-humanist perspective to the problem of physical disability by approaching the use of assistive technologies (AT) by disabled people as the introduction of a low-tech cyborg in the world. In doing so, we highlight examples of communication ATs and provide analogies between ATs and languages in the constitution of selves and social contexts. ATs are informed ideologically, so they can be seen both as a way to "fix" an "impaired" person, or as a strategy to overcome a physical and social context that disables some people and makes other people "able-bodied". We argue that becoming a lowtech cyborg can be a form of social inclusion if we understand disability to be produced by the context, rather than as an inherent dysfunctionality of the individual. Based on this assumption, we identify two strategies of social inclusion of the low-tech cyborg: disembodiment of the Self, and embodied virtuality. We remark, however, that low-tech cyborgs can be configured out of necessity or choice and add that the same socioeconomic factors that produce inequality in general are also active in the social exclusion/inclusion of the low-tech cyborg. Thus, ATs can be adopted and transformed by choice so as to broaden the gap between cyborg haves and have nots, while both kinds of cyborgs can become increasingly subject to cognitive and affective exploitation in the context of cognitive capitalism. We conclude that the potential of a post-humanist perspective to disability should not be about making "impaired humans" integer, nor making "integer humans" more than human, but keeping selves ethically connected with others whether by virtual embodiment or embodied virtuality.
\end{abstract}

Keywords: low-tech cyborgs; disability; social inclusion.

\footnotetext{
* Royal Melbourne Institute of Technology - RMIT, Melbourne, Australia. elizabeth.kath@rmit.edu.au, https://orcid.org/0000-0002-7531-7278

** Royal Melbourne Institute of Technology - RMIT, Melbourne, Australia. osorio.neto@rmit.edu.au https://orcid.org/0000-0001-9090-473X

*** Ministério da Ciência, Tecnologia, Inovações e Comunicações, Brasília, Brazil.

**** University of Campinas (UNICAMP), Campinas, Brazil. mbuzato@unicamp.br, https://orcid. org/0000-0001-5998-5930
} 


\section{RESUMO}

Este artigo discorre sobre as consequências de uma perspectiva pós-humanista para o problema de deficiência física, abordando o uso de tecnologias assistivas (TA) por pessoas com deficiência como a introdução de um ciborgue low-tech no mundo. Ao fazê-lo, destacamos exemplos de TAs de comunicação e fornecemos analogias entre TAs e línguas na constituição do Self e do contexto social. TAs são informadas ideologicamente, de modo que podem ser vistas tanto como uma maneira de "consertar" uma pessoa "incapacitada", quanto como uma estratégia para superar um contexto físico e social que incapacita algumas pessoas e torna outras pessoas "capazes". Argumentamos que tornar-se um ciborgue low-tech pode ser uma forma de inclusão social se entendermos que a deficiência é produzida pelo contexto, e não uma disfuncionalidade inerente ao indivíduo. Com base nesse pressuposto, identificamos duas estratégias de inclusão social do ciborgue low-tech: desincorporação do Self e virtualidade corporificada. Destacamos, no entanto, que ciborgues low-tech podem ser configurados por necessidade ou por escolha e acrescentamos que os mesmos fatores socioeconômicos que produzem desigualdade em geral são ativos na também na sua exclusão/inclusão social. Assim, TAs adotadas por escolha podem se transformar em uma maneira de ampliar o fosso entre ciborgues ricos e pobres, sendo que os dois tipos de ciborgues podem estar cada vez mais sujeitos à exploração cognitiva e afetiva no contexto do Capitalismo Cognitivo. Nós concluímos que uma perspectiva pós-humanista da deficiência não é sobre tornar inteiros "seres humanos com deficiência", nem sobre tornar "humanos inteiros" mais do que humanos, mas sobre como manter o Self e o outro conectados eticamente, quer em condicoes de desincorporacao do Self, ou de virtualidade incorporada. Palavras-chave: ciborgue low-tech; deficiência; inclusão social.

\section{INTRODUCTION}

An article that appeared in The New York Times on 23 March 2019 is titled 'Human Contact is now a Luxury Good'. It opens with a story about a man named Bill Langlois, who is a 68-year-old retiree living in a low-income senior complex in Lowell, Massachusetts. After retiring from operating machines, Mr Langlois found himself aging at home. With his wife unable to be at home often, and his needs for care increasing, he became lonely. That is, until he made a new friend. According to Mr Langlois, his new friend gave him a new lease on life. "I found something so reliable and someone so caring, and it's allowed me to go into my deep soul and remember how caring the Lord was," Mr Langlois says. "She's brought my life back to life" (BOWLES, 2019).

Mr Langlois' new friend is a cat called Sox; a simple animation that barely moves and that speaks to him through the screen of a tablet in a harsh robotic voice. Sox the cat was brought to Mr Langlois by a non-profit company called Element Care, which offers Sox the CareCoach as part of a health care program for older adults on low incomes. A video feed is fixed permanently on Mr Langlois in his recliner, while overseas workers (mostly in Latin America and the Philippines) 
watch, listen, and type Sox's responses (BOWLES, 2019). Even with what little we know of Mr Langlois' life, we could argue that he is a 'posthuman'.

\section{POSTHUMANISM AND THE 'LOW-TECH CYBORG'}

If it is embodiment (a clearly defined self, contained within our flesh and blood) that makes us human, then we become 'post-human' when our 'self', including our consciousness and identity, moves beyond our human body and into technological platforms that distribute us across time and space (MAHON, 2017, p9). Griffin (2017) defines posthumanism as "a worldview and moral position that no longer regards the human as at the centre of the universe and as the dominant and determining being. Derived from moral philosophy, applied ethics, and technoscience, posthumanism stresses the interrelation between human, machine, animal, and environment."

The notion of human beings as integrated with technological devices has, at least since the 1960s in scientific literature (although far earlier in science fiction), conjured ideas of the super-human 'cybernetic organism' or cyborg (CLYNES \& KLINE, 1960; HALACY, 1965). What we mean by posthuman, in this case, is not the more-than-human, self-directed, self-transformed creature of (libertarian) transhumanism (MORE, 2003), a self who has been able to transcend its biological predicament by taking over the management of its evolutionary process. Nor do we refer to the philosophically and discursively decentred human subject of philosophical/critical posthumanism (BARAD, 2003; BRAIDOTTI 2016), a human whose exceptionalism is in question in the face of the Anthropocene, genetic engineering, artificial intelligence and other historical developments that shatter ontological polarizations such as nature-culture, human-technology, and matterdiscourse. What we mean by posthuman is both and neither; that is, the human subject as "an assemblage, co-evolving with other forms of life, enmeshed with the environment and technology" (NAYAR, 2014, p4).

Inasmuch as $\mathrm{Mr}$ Langlois's sense of being (him)self depends on his enmeshment with an environment sustained by the work of machines, we might, more properly, deem him a cyborg - a cybernetic organism. Mr Langlois is not though, one of those sophisticated human-machine hybrids that fly spaceships or fight wars against aliens in Sci-Fi genres. Rather, he is what Hess (1995) calls a "low-tech cyborg". What makes Mr Langlois's example particularly worth citing here, is that his sense of self is extended through participation in discourse in an environment coproduced by his senses and environmental sensors or scanners, and 
his remote interlocutors constituted as human-plus-computer conversation agents represented to him as multimedia characters.

In fact, some have argued that most people, whether they are deemed disabled or not, have now become 'low-tech cyborgs', in that we rely on technological devices that are integrated into our basic daily activities, and that operate as techno-social objects mediating our relations with other human beings. David Hess's 1995 essay "On low-tech cyborgs" introduces this idea:

I think about how almost everyone in urban societies could be seen as a low-tech cyborg, because they spend large parts of the day connected to machines such as cars, telephones, computers, and, of course, televisions. I ask the cyborg anthropologist if a system of a person watching a TV might constitute a cyborg. (When I watch TV, I feel like a homeostatic system functioning unconsciously.) I also think sometimes there is a fusion of identities between myself and the black box (HESS, 1995, p. 373).

The internet, to which most people are now constantly connected via smartphones, has since extended human cognition further beyond the body, allowing artificial memory via digital calendar appointments that send us reminders, access to factual information (via the Google search) beyond what our brain could retain, and it allows us effectively to be in different places at the same time (MAHON, 2017: p. 7-8). Peter Mahon refers to the smartphone as a "cognitive prosthetic", and invites us to imagine what it might be like to suddenly find ourselves without it (2017, p.7-8).

You'd very likely survive without it... but wouldn't your life nonetheless be impaired somewhat by losing it?... Would you trade, say, a toe (a finger? a kidney?) to have back what your phone gave you? Even if you wouldn't trade a toe to have your phone back, if you think that losing your phone might be like losing a part of you that you'd mourn, then you're already posthuman, because you're no longer conceiving of yourself in purely biological terms, no longer thinking about yourself in terms of a purely human body, but in digital technological terms as well. In other words, you've begun to think of yourself as extended or distributed across flesh and blood and silicone, data networks and radio waves (MAHON, 2017, p. 8).

In the introduction to his "Cyborg Handbook", Gray (1995) suggests that human-machine cyborgs can be of four kinds: restorative, normalizing, enhancing, and reconfiguring.

The restorative cyborg, perhaps the most visible kind, is constituted by the addition of a synthetic element to a biological body in order to restore one or more of its lost or missing functions. That description would fit someone with a prosthetic limb or even an elderly person wearing glasses. The normalizing cyborg is the product of a restoration process that makes it indistinguishable from the "normal" biological creature, such as, for example, someone with a pace-maker implanted in their chest 
or on a daily dispensation of lithium that keeps their moods within the acceptable boundaries of social conviviality. These two categories of cyborg - the 'restorative' and the 'normalizing' - fit what we can call a class of cyborgs "out of necessity".

An enbancing cyborg is one where the added element seeks to make the biological counter-part stronger, faster, smarter or longer lived, even though there would usually be considered nothing missing or 'abnormal' about the human body involved. Suitable examples might be the cases of Olympic athletes wearing stateof-the-art suits, shoes, glasses or poles, human plus artificial intelligence stock traders or military engineers who design mind-controlled exoskeletons. Finally there are reconfiguring cyborgs, those which do not hold on to the established idea of the human in order to restore, normalize or enhance it, but wish to reinvent the human as proto-biological creatures who can overcome environmental and evolutionary obstacles beyond human possibilities or in inhuman conditions. Examples might be bioengineering humans that can feed on inorganic matter, or preserve human selfhoods beyond the confines of a biological substrate, as in mind uploading projects. These two categories of cyborg - the 'enhancing' and the 'reconfiguring' we can call cyborgs "by choice".

By contrasting consumptive (by choice) and necessitative (by necessity) cyborgs (CASE, 2010), we can easily relate the low-tech cyborg to the concepts of social inclusion/exclusion. At first glance, this would be just another case of haves (consumptive) versus have-nots (necessitative), but this becomes more complicated if we consider that cyborgs are means and the products of both dependence and independence. Whereas cyborgs by necessity need to be restored or normalized to (re)gain a certain degree of autonomy and/or selfhood (which, in many cases they can't afford, either financially or in other ways), cyborgs by choice become increasingly dependent on their add-ons to retain their status or levels of performance. Those add-ons or reconfigurations have to be constantly updated due to the very consequences of these new, enhanced and reconfigured agencies, in the world. In that sense, and since they have no "original" selfhood to come back to, their voluntary integration with technology renders them constantly at risk of exclusion.

\section{DISABILITY AND ASSISTIVE TECHNOLOGY}

While we have become collectively fascinated over recent decades with the incorporation of machines into our everyday lives, for some people the experience of integrating machines with the biological body is not so novel or romanticised. 
"For people without disabilities, technology makes life easier. For people with disabilities, technology makes life possible" were the words of Mary Pat Radabaugh, former Director of IBM National Support Centre for Persons with Disabilities in 1988 that have been repeatedly quoted since, and can be found scattered across countless online articles and websites relating to assistive technology and disability. Yet surprisingly, there has been a conspicuous absence of disabled people who become cyborgs (those thought of as restorative or normalizing cyborgs) from much of the relevant scientific literature (REEVE, 2012; MOSER, 2000; 2005). "Ironically, while the cyborg is supposedly about 'transgressed boundaries' and 'potent fusions', the starting point in any cyborg discussion is inevitably a 'fully functioning human and a fully functioning machine' (QUINLAN \& BATES, 2009, p. 51), an assumption which remains invisible and unquestioned" (REEVE, 2012, p. 91).

Reeve argues that one factor potentially contributing to this is that technology has, for people with disabilities, a history of negative association with "normalization, rehabilitation and cure" (2012, p. 91). To understand this association, and indeed the disconnect between the way we think of technological body enhancement in relation to people with disability as compared with the so called 'able-bodied', requires some historical context regarding the construct of disability.

Until at least the 1970s, disability was ideologically approached with what is now known as the 'medical model of disability'. The 'medical model' treats disability as a functional problem of the individual that restricts what a person can do or be. The human body is conceived in the way a machine would be, with a set of functional norms; as such, disability is viewed as a failure or malfunction. This approach framed people with disabilities as deficient human beings, or at worst as pariahs or freaks (BARNES \& MERCER, 2001; COCO, 2010; OLIVER, 2012), condemned to social segregation. Disability under the medical model is seen as a problem of the individual, requiring the intervention of medical professionals to care for, rehabilitate or 'fix' the disabled person (PWDA, 2019). Further, the assumption is that impairment "encroaches on the psychic life of the disabled person [and] that disability is internal, inaugurating a crisis within the person's bodily or cerebral self" (CAMPBELL, 2009, p. 34).

By contrast, the social model of disability emerged as a reaction to the medical model, and was intended to reframe the way disability is understood and contextualised. The term 'social model of disability' was coined by British disability advocate and sociologist Michael Oliver, who argued that most of the difficulties that people with disabilities face derive not from the individual's physical or 
intellectual condition, but from the social environment that is constructed in such a way that it is accessible for some bodies and exclusionary of others (whether directly or indirectly) (MITRA, 2006). In other words, it is the social environment that requires change in order to allow people with disabilities to experience a full life (OLIVER, 2012). An important step in the process of reframing disability was a distinction between the terms 'impairment' and 'disability' made by an early UK disability rights organisation, The Union of the Physically Impaired Against Segregation (UPIAS). The founding statement of UPIAS says: "What we are interested in, are ways of changing our conditions of life, and thus overcoming the disabilities which are imposed on top our physical impairments by the way this society is organised to exclude us" (UPIAS, 1972). In other words, "impairment" is an individual biological condition, whether congenital or acquired (accident, disease, aging etc.) (SHAKESPEARE, 2013, p. 16), whereas "disability" often arises from the individual's social context. It is the outcome of impairment (OLIVER, 2012) or the inability (JENKINS, 1998) to execute properly the tasks considered ordinary for a human being (COOK \& HUSSEY, 1995) and this is often a problem of social context.

The constructed category of so-called 'able bodied' people is one that always involves physical and intellectual limitations and where there are vast physical and intellectual variations. Without technological intervention, the 'able bodied' cannot fly, or breathe underwater, or survive without sleep. Accordingly, the social context is constructed to allow for these limitations. Nor is it possible for any person to ever reach or express their full physical and mental capability, because context also creates limitations. It is virtually inconceivable, for example, for a person to have learned to play every sport in the world, or to communicate freely in every existing language.

The analogy with language is useful here as far as we agree that a language is not a mental structure per se, but the social use of this structure or faculty for a variety of purposes, including self-reflection. To be illiterate or not to speak the language of the social context where one is subjectified is to be disabled, in a way, but not impaired, unless in the case of a sever aphasia or other brain-related diseases. So what one does or feels when she lacks a literacy or a foreign language in that context is not meaningless or useless per se, but only disconnected from a proper context where its meaning could be interpreted. A piece of prosthetics could be considered as a translator or a dictionary, in this sense. It reconnects the self to the social context, but not necessarily in such a way as to make the disabled person "fit in" as if the impairment were not there. What it does is to provide a means 
of reconnection that makes the demands of the self and the context negotiable, reconfiguring both to a certain extent, even if momentarily.

If we return to the example of Mr Langlois and Sox the Cat, we could say that Mr. Langlois was reassembling a social context through a screen and its talking interface figuring a remote human labourer. Even though the animation is a simulation or representation that gives a face to voices of people who live on the other side of the world, and are, thus, outside of his physical environment, those people nevertheless became his social context. Mr Langlois (seen as a cyborg) reenabled a social context which, even if it was different to that which he had before, remediated his disability regardless of his impairment.

Given the theme of disability, the example of sign language is particularly illustrative of the difference between impairment and disability because it uses the same human language capacities any verbal language does, but changes the material nature of the signifiers and the sensorial channel that is uses predominantly. In a context where everyone is deaf, sign language is seen as a normal language. People have arguments, tell stories, develop slang, nicknames, flirting lines, swear words, and even different sign languages and dialects in different parts of the world, which can be translated either to spoken languages or other sign languages. Thus, if a deaf person's context does not include any sign language speaker, then sign language becomes nothing more than gestures just as any other foreign language can only be perceived as sounds by one who does not understand it. In such a context, the impairment of being deaf becomes a double disability. Literally, in this case, a translation device, or speech to text device or a translator, could be prostheses that reconnects the deaf person to her selfhood.

By reconnecting to the social context, one reconnects to oneself. The prosthetic limb or the tablet or the wheel chair, is not a way to restore a self, but a bridge to the context which re-enables the self. This is no different from what happens to a speaker in her own community; only language is not a machine, but a permanent means of connection and readaptation of the context to the self and vice-versa. Language both evokes context and provides context for other talk (GOODWIN \& DURANTI, 1992).

The long term efforts of disability advocates has been fundamental to changing the way disability is framed, and building political and social recognition and support for rights of people with disabilities. As of November 2018, the Convention on the Rights of People with Disabilities was ratified by 177 countries. The document, which was adopted in 2006 and was the first comprehensive human rights treaty in the $21^{\text {st }}$ century, introduced important policies, including regarding 
the use of technologies suitable for persons with disabilities in habilitation, rehabilitation, mobility and participation in political and public life (UN, 2006).

For people living with impairments that prevent them from carrying out functions that most take for granted, the integration of the biological self with machines or devices (broadly termed 'Assistive Technology') has a long history. According to Bluebird Care, an Assistive Technology (AT) provider which designed a comprehensive AT timeline, the history of AT dates to Egyptian mummies, in which artificial toes were found; reputedly the very first prosthesis. Evidence of the first wheelchair was found in China, dating to 525 A.D. (GOOSEY-TOLFREY \& MINETTI, 2005) and hearing devices take us back to 1874 (EDYBURN, 2001, p. 96).

Assistive technology is technology intended to provide its user with greater freedom; to enhance, liberate, and reorganize the lives of people with disabilities, allowing enhanced capacity to perform everyday activities and integrating these enhanced capabilities into everyday life. AT has been defined as "any item, piece of equipment or product system whether acquired commercially off the shelf, modified, or customized that is used to increase, maintain or improve functional capabilities of individuals with disabilities" (COOK \& HUSSEY, 1995, p. 5). AT devices may be items we would now consider very low technology (a cane, eye glasses, an ancient prosthesis) or high technology (electronic communication devices, augmented reality devices and electric wheelchairs).

AT innovations can be shaped by the ideological model that informs them. AT intended to "fix" a disabled person (as conceived under a medical model approach), is likely to produce different technology to that which is designed to eliminate the social barriers. The adaptation of AT innovations is also affected by social context. A communication device or wheelchair could "fix" a mobility impairment and enable a person to experience a park, travel to university, or drive a car. Yet, those interventions also rely on a wider environmental context. A communication device will not work properly without supporting technological structures such as optical fibers, platforms, transmission towers and satellites; a wheelchair will not be able to move through parks and buildings without access ramps. The same technology that is designed to resolve an impairment could be underused or useless without a wider context to support it. Assistive technologies can also create dependencies on machines that undermine human freedom in unintended ways, and can carry stigma, which, like the application for disability benefits or compensation, "can generate feelings of despondency as the disabled person engages in a process of altered 
perceptions and puts on the clothes of a disabled identity" (CAMPBELL, 2009, p. 35; HOLLOWAY, 1994).

\section{DISABILITY, (DIS)EMBODIMENT, AND SOCIAL CONTEXT}

Disability studies have clear relevance, and crucial contributions to make, to discussions about posthumanism. As Nayar argues, disability studies (along with animal studies, monster studies, cybernetic and consciousness studies) "redefine the boundaries of the human and call into question the hierarchies of human/ non-human, human/machine and human/inhuman" (2014, p. 14). The literature on posthumanism, including the concept of the 'low tech cyborg', brings to light the $21^{\text {st }}$ century reality of increasing disembodiment and/or virtual embodiment (HAYLES, 1999); an ever greater reliance of all human beings on technological devices to perform the fundamental daily activities (communicating, ordering food to eat, dating, navigation, travel and so on) such that, arguably, without those devices we, low-tech cyborgs by choice, would all be rendered 'disabled'.

This has provided fertile ground for many to conceive of a future in which the construct of the 'human' - the identity as contained within a human body - has been extended and reconfigured to the extent that the construct of the 'disabled person' is also being rendered obsolete. This is a view that American engineer and biophysicist Hugh Herr shares. In a 2018 Ted talk titled "Becoming a Cyborg: From Disabled to More-Than-Able", Herr (who lost his legs in a mountain climbing accident and paces the stage with two advanced bionic legs) argues that we will be able "to officially do away with disability altogether in the 21 st century". This will be achieved, he argues, through "the radical transformation of humans into cyborgs". In Herr's view, he is not yet a cyborg because he cannot yet feel his prosthetic legs. Becoming a 'real' cyborg, according to Herr, would require sensory integration of the bionic device technology with the biological self. Herr (2018) sees this as the tipping point at which physical disability is rendered obsolete, or, in other words, to be fully aware of one's context, in this case one's proprioception and physical contact with the environment would make restorative cyborgs more than normalized; that is, normal, even if different.

Yet even if sensory integration of the kind that Herr conceives (being able to 'feel' a bionic device) is not yet a reality, this may not be so crucial to the redefining of disability, given that technology is already effectively reconfiguring and blurring the boundaries between the categories of 'disabled' and 'able' human bodies. We have all become 'low-tech cyborgs' through our greater dependency on many of the 
same technologies, and the usage of everyday devices is becoming less dependent on being 'able-bodied', particularly given the improved accessibility features.

This brings us back to the question of cyborgs and inclusion/exclusion processes. Although there are differences in the way devices are used, it is arguable that technology has inclusive potential and is building a common ground on which all people can interact (IRWIN, MARY \& SESTO, 2012, p. 1042). Further, we are also seeing a progressive convergence between assistive technologies - or "alternative technologies" - into mainstream technologies. Devices once designed for specific uses among people with disabilities now reach wider consumer bases. Solutions designed to allow people with hearing difficulties to watch TV, for example, led to the Ceefax Teletext, and Apple's Siri was based on early voice recognition software. What is needed for those deemed disabled becomes a voluntary option or choice for the enhancement of the able-bodied.

On the other hand, mainstream devices are also being used for treatment of people with disabilities, and in Assistive Technology (AT) research and development. For example, Irwin and Sesto (2012) conducted a study where participants with movement disorders interact with touch screen devices. The objective was to provide engineers and designers with a more inclusive perspective in order to improve the design of future devices. Chang, Chen, and Huang (2011) demonstrated the possibility of adapting equipment originally designed for an interactive videogame to help rehabilitate people with motor impairments. In other words, in addition to the reality that all people are becoming dependent on devices, we are also seeing a blurring of the lines between technological innovation for people with disabilities (AT) and that intended for the general population. What facilitates or enhances the included often becomes what the excluded have long needed.

Disembodied forms of human engagement and their relation to inclusion/ exclusion are increasingly the norm of the $21^{\text {st }}$ Century. Helpful in understanding how we arrived here is the work on 'technologically extended forms of the social', or 'constitutive abstraction' by Australian social theorist Geoff Sharp (1985, and especially 1993), and others who have continued to develop his approach (see JAMES, 1996; JAMES 2014; JAMES \& KATH, 2014).

Geoff Sharp (1993) theorises an historical shift from pre-modernity through to post-modernity, through which new forms of technologically extended social integration came to dominate through the rapid proliferation of abstracted modes of intellectual exchange (from writing through to telecommunications). Following in this vein, globalisation theorist Paul James (1996, p. 23) identifies four levels 
of social integration: the face-to-face, the object extended, the agency-extended, and the disembodied.

The face-to-face refers to the realm of tangible, embodied co-existence and of identity based on kinship. Tribal societies have been predominantly structured around the face-to-face, and of a sense of being directly and tangibly present with and connected to others, even in their immediate absence. As the primordial form of social integration, the face-to-face underpins and is embedded in more abstract modes of integration, which make constant reference back to it. Object extension emphasizes the way in which objects come to draw relations between people across time and space; these objects can be personal, sacred or commodified.

Agency-extended integration is that which is extended and mediated through institutions; it renders relations between people as more universalised, but, nevertheless, still bounded by extensions of the body. Through institutions (such as the state or the church), people can be bound together conceptually without knowing each other at the face-to-face level, and the increasing dominance of these modes of institutionalized integration marked the transition to modernity and to the rise of the nation-state. In describing the nation as an imagined construct, James observes that "members of even the smallest nation will never know most of their fellow-members, meet them or even hear of them, yet in the minds of each lives the image of their communion" (1996, p. 6).

Most relevant to this discussion though, is the fourth modality of social integration, the disembodied, which is made possible through technology that allows engagement with the world in a way that is disconnected from the face-to-face, thereby bringing a profound reconstitution of social relations (JAMES, 1996; JAMES \& $\mathrm{KATH}, 2014)$ ). This reconstitution of social relations through technological extension and mediation means that our social presence can now exist in places far away from our physical presence. Everything is there, but our body and mind are here (HEETER, 2000, p. 6). The social implications of this disembodiment are profound, affecting the terms on which we can relate to others, the way we are perceived, the communities we become members of, and what we are capable of.

In other words, it affects the idea and the workings of context profoundly and, thus, what counts as disability. Therefore, for people with disabilities, the terms of engagement and inclusion have changed in the online era. A BBC article by Vicky Schaubert (2019), titled "My disabled son's amazing gaming life in the World of Warcraft" provides a poignant and moving example.

Mats Steen was known as Lord Ibelin Redmoore and sometimes Jerome Walker; he was a warrior in World of Warcraft, a popular game that connects 
people from all around the world to play together online on a single platform. Participants can define their identity in the game, including their physical characteristics (hair, eye colour, gender, body type and so on). Players can play alone or join guilds or teams. For more than 12 years, Mats was a member of 'Starlight' - a group with about 30 members. Since the friendships between members of Starlight were conducted online, for years Mats' group members were not aware that he had Duchenne muscular dystrophy (DMD) - a rare disorder causing muscle degeneration - or that he lived in a wheelchair, barely able to leave the house.

At the age of 25, in 2014, Mats Steen died from his condition. Not long before his death, he started writing blog about his experiences in World of Warcraft. It was there that he revealed his material body's condition for some online players who had become closer to him. "There my handicap doesn't matter, my chains are broken, and I can be whoever I want to be. In there I feel normal," he wrote. It was only after Mats died that his parents became fully aware of the extent of his online life, when they began to receive a stream of emails from Mats' online friends, expressing their grief and condolences. While Mats had been housebound for years and therefore barely knew anybody in his local town in Denmark, his online Warcraft friends pooled money to travel from around Europe to his funeral to pay homage. Other members of his team all around Europe held a candlelight vigil for him, and the Starlight group has continued to hold a memorial service for Mats every year since.

During his life, Mats was able to escape his physical limitations by means of virtual embodiment; one way of becoming a cyborg for Hayles (1999). "It's not a screen", Mats wrote. "It $>s$ a gateway to wherever your heart desires." The game became a metaphysical extension of Mats' corporeal body that also preserved his agency in an enabling context; a place where he could walk, communicate, lead, and kill monsters, leave his room without any difficulties or assistance, shape his identity on his own terms, and express himself in ways that otherwise might not have been possible.

While social theorists such as Sharp (1993) have long talked about the different ways through which language, interaction and embodiment can relate to one another in different modes, or levels, of social agency that promote different dimensions of social inclusion/exclusion, looking at disability through the lens of posthumanism seems not only to make these views more tangible, but also to encourage a reconceptualization of what counts as inclusion/exclusion when contexts are sustained by immaterial flows of information patterns, and virtual embodiment counts as normalization, given the appropriate setting. However, 
social contexts are not either physical or virtual, but both, as are bodies and social relations. Nor can peopless power to act and change the context in the material world manifest as freely in the world of institutions as it can in World of Warcraft. One can much more easily purchase the power to fly in the game, or earn it by completing a few quests, than have a staircase replaced by an elevator in a public building or convince a congress person to pass a law requiring an audio description track on every TV program. There is a dark side to the cyborgization of the selves and the exchanges of need for choice in the posthuman society that needs to be considered, so we donst indulge in a fantasy of the posthuman as the end of our ethical responsibility towards ourselves and other humans, able-bodied or not.

\section{INEQUALITY AND THE DARK SIDE OF THE LOW-TECH CYBORG}

Mats' story provides an example of the way online worlds can allow an escape from the excluding physical realities of the embodied world. That is, at the same time, a trajectory that starts at impairment, makes a stop at disability, as participation in the game provides a context for him to establish a sense of selfhood in a social context that does not segregate him, and ends in restoration, or even enhancement through the virtualization of his body and the exercise of his agency by means of algorithms and multimedia languages.

For people with disabilities, there are also many compelling reasons to be optimistic about technologically mediated life of the $21^{\text {st }}$ century, including the argument that all people are becoming technologically dependent and therefore are less differentiated by the limits of their physical bodies. Yet the levelling out of human physical capabilities as they become increasingly interwoven with augmenting technologies is only one consideration in imagining a closing of the divide between the 'disabled' and the 'able-bodied'. Even if technologies are now integrated into all of our everyday lives in way that levels us, this does not automatically resolve the legacy of the social stigma that excludes, marginalises, and disables. In elaborating Geoff Sharp's theory of technologically extended social relations, Paul James emphasises that the embodied still exists, simultaneously with the disembodied. What Sharp and James call 'different modes of social integration' are not distinct from one another, but are woven across one another to form the fabric of the contemporary social world (JAMES, 1996). There are new frontiers for our social presence, but the embodied is always embedded within it; it does not disappear. 
Likewise, cyborgs are heterogeneous and technologies are not socially neutral: they embed or at least support values, both positive, like fairness or community, and questionable values such as individualism, managerialism, utilitarianism and so on. Moreover, technologies come at different prices and technical capabilities, which makes them work as class distinction symbols and provides further advantage to those who are already privileged, in the sense that they can afford constant upgrades, subscriptions, devaluation and so on. There are also new forms of inclusion and exclusion among the normalized, restored, enhanced and reconfigured, just as there still are among genders, social classes, ethnic groups and so on.

A recent study by Meyer and Asbrock (2018) examined stereotypes of people with disabilities using devices alongside able-bodied people using devices. They used the Stereotype Content Model wherein the attributes of 'warmth' and 'competence' are core dimensions of stereotypes. According to this model, people with disabilities are often stereotyped paternalistically as warm-but-incompetent. The historical legacy of the disability construct is as the corporeal representation of social incompetence, as the opposite of having "capabilities, potentials and adequacies" (JENKINS, 1998, p.1), a social and cultural construction that relegated 'Others' who do not conform to the normal (GOODLEY, 2014, p. 6).

Meyer and Asbrock's (2018) hypothesis was that the proliferation of bionic technologies (not only those typically associated with disability such as arm and leg prosthesis etc., but also those more mainstream technologies such as retina implants) carries potential to reduce or eliminate negative stereotypes towards people with disabilities. Such devices, they argue, are often associated with competence in the way they are portrayed in the media and popular culture. They proposed that people with disabilities (PWD) who use bionic prostheses were likely to be perceived as more competent than PWD who do not, and possibly also as more competent than able-bodied individuals. They also expected to find that those using bionic prostheses would be perceived as less warm, especially when the label 'cyborg' was applied. Meyer and Asbrock's study produced mixed results in relation to their hypotheses:

People with physical disabilities who use bionic prostheses are seen as more competent than people with physical disabilities in general, but not as more competent than ablebodied individuals. They are perceived as even warmer than able-bodied individuals. On the contrary, cyborgs were perceived as competent-but cold, i.e., as threatening (MEYER AND ASBROCK, 2018).

Meyer and Asbrock remained optimistic about the potential of technology to affect stereotypes and interpersonal perceptions. However, their results 
demonstrate that a gap persists between the perceptions of people with disabilities and able-bodied people.

Apart from the persistence of such a gap, if you are a cyborg "by choice", it counts as higher status or empowerment, maybe boldness, updatedness or other positive qualifications. The added non-human does not reduce inequality, it extends inequality further. If the necessitative cyborg is seen, by the prejudiced eye bound to the medical model, as a less-than-able or less-than-integer body, then the addition becomes a subtraction, so to speak: the more non-human elements you add, the farther from integer one becomes. Thus, Cyborgs are subjectified in the same social fabric as those considered "entirely human" are, so the baseline for inclusion/ exclusion remains.

In fact, if we go back to social model of disability that sees the context as the disabling element, and if we understand that the our social peers are, in the end, the core of what we call "the context", this means those who become enhanced by choice, as a form of distinction or self-empowerment, disable even the "normal" by creating a context where the other and I are not "interoperable". If an analogy with language applies here, this would mean that some cyborgs would be like multilingual, cosmopolitan speakers, whereas others would be monolingual with "an accent" that stigmatizes them.

Thus, while there are positive stories about the liberating effects of technologies, including the story of Mats Steen and World of Warcraft, some are less optimistic about the emancipatory potential of new technologies. Technology reporter Nellie Bowles, who wrote the New York Times article about Mr Langlois and Sox the Cat, points out that service delivery programs like that of Sox the cat are proliferating, not necessarily because they are better than their face-to-face equivalents, but because digital services are cheap:

Life for anyone but the very rich — the physical experience of learning, living and dying — is increasingly mediated by screens. Not only are screens themselves cheap to make, but they also make things cheaper. Any place that can fit a screen in (classrooms, hospitals, airports, restaurants) can cut costs. And any activity that can happen on a screen becomes cheaper. The rich do not live like this. The rich have grown afraid of screens. They want their children to play with blocks, and tech-free private schools are booming. Humans are more expensive, and rich people are willing and able to pay for them. Conspicuous human interaction - living without a phone for a day, quitting social networks and not answering email — has become a status symbol (BOWLES, 2019).

Choice or context, including the choice of virtual embodiment (as in cyborgs by choice) or embodied virtuality (as in Mats's normalizing game setting) is, like anything else in capitalist societies, up for purchase, so whereas the rich can choose 
to move across contexts and virtual or flesh-and-bone (en)able(d) bodies as they please, the disabled, both physically and financially, struggle with the need to 'stay in context' as institutions become more and more virtualized. This is arguably a very 'sophisticated' kind of social exclusion produced quietly and justified by the same values the digital computerized technologies support: managerialism, utilitarianism and so on. The concept of disability, in this sense, is not disappearing as cyborgs multiply, but being reconfigured. Likewise, the inclusion/exclusion of the disabled needs to be addressed in new ways.

During the decades when digital technologies first emerged, access to the latest gadget was a symbol of wealth and status, for individuals and institutions. Schools and universities became obsessed with introducing the latest technological equipment and digital learning platforms. Schools competed to provide every student in the room with the latest laptop; universities introduced online course offerings that no longer required students to be physically present on campus or attend lectures or tutorials.

As these gadgets become cheaper to produce and buy and ubiquitously owned, it is arguable that their novelty is wearing thin, and their socially alienating, or even anti-social, effects (MILLER, 2012) are becoming more palpable. Despite technologies that make us more 'connected' than ever before, Western industrialised countries are experiencing an epidemic in loneliness and social isolation (HAMPTON, SESSIONS, HER \& RAINIE, 2009; KIM, LAROSE \& PENG, 2009; MUHAMMAD, SCHNEIDER, HILL \& YAU, 2019; SINGH, 2019), which, like any other contemporary human problem, is perceived as solvable through more sophisticated technologies such as sexbots (DEVLIN \& LAKE, 2018) or robots as caretakers for the elderly (FOSTER, 2018).

We are living in the context of cognitive capitalism, that is, a mode of production and accumulation of capital centred around the accumulation of immaterial assets, immaterial (intellectual, data generating, knowledge dissemination) labour, as opposed to industrial capitalism, in which wealth was generated through the accumulation of physical capital and the mass production of standardised goods (MOULIER BOUTANG 2011; EMERY, 2011). There is an ever-growing role for "disembodied" products and services, which affects health care just as much as it affects industry, commerce and agriculture. This mode of production is geared towards capturing the innovation present in the interactive cognitive and semiotic processes of social cooperation and the tacit knowledge of device and software users at large. 
This means that users of digital technology, seen as cyborgs, become roundthe-clock immaterial labourers and co-producers of innovation, no matter whether they are in the office typing or navigating on the web in front of their lap-tops, at the beach checking their social media updates on their tablets, wheel-chairing with the GPS signals on their mobiles on or even lying in a hospital bed talking to a robot. These cyborgs, as well as others, embody the immaterial labourer in a system that evolutionist economists propose is put in motion by three types of inputs: hardware (the physical layer, including biological bodies), software (the logical layer, including algorithms and data structures), and wetware (the living brain layer) (MOULIER BOUTANG 2011; EMERY, 2011).

Many industries that previously required constant face-to-face interaction and physical movement now require workers to spend long hours daily in front of screens, virtually chained to their desks, resulting in new occupational health epidemics. The human body is not designed to sit without moving all day, and our new work lives in front of screens may be slowly killing us, with long periods of inactivity associated with many chronic diseases such as obesity, cardiovascular disease, Type 2 diabetes and premature death (HAMILTON ET AL, 2007; WITTINK ET $A L, 2011)$. When the able-bodied become low-tech cyborgs through their need to connect with their increasingly technologically mediated social context, their biological dimension pays the price of abandonment in a deserted face-to-face context. This abandonment tends to debilitate the "wetware", creating the demand for even more prostheses that produce data and disseminate information (calorie counting tread-mills, apps for recording medical records, internet queries that serve as proxies to the user's level of anxiety or depression) to 'normalize' or reintegrate the compromised body, providing further demand for profit-driven technological innovation and immaterial labour typical of cognitive capitalism .

Attempts to mitigate the workplace hazard of sitting in front of screens have come in the form of a boom in popularity of the 'standing desk', ergonomic chairs and keyboards and so on. None really solve the fundamental problem of our everdeclining physical activity. Digital devices have also been blamed for increased mental health problems, including stress, anxiety and depression. Australia's depression support website, Beyond Blue, advises readers of 'the benefits of digital detox' (BEYOND BLUE, 2019). The World Health Organization (WHO) in 2018 classified "gaming disorder" as a mental health condition in the 11th edition of its International Classification of Diseases Manual (WHO, 2019).

It is no surprise either that the dawn of the $21^{\text {st }}$ century has also seen a boom in popularity of 'mindfulness' practice and other forms of meditation in the West, 
YouTube fitness bloggers, and (for those who can afford them), personal trainers and luxury resorts offering digital detox holidays. Digital detox rehabilitation centres have sprung up around the world to treat the growing problem of online gaming and social media addictions (BREWSTER, 2016). In China, the problem of digital addiction has become so extreme that parents have resorted to digital boot camps for their addicted children (BROWN, 2016; PHILLIPS, 2017). In 2011, it was widely reported that a Chinese man died after internet gaming for three days straight. In 2015, another man died in a Shanghai internet cafe after playing World of Warcraft for 19 hours continuously (BROWN, 2016).

And yet there are powerful economic interests invested in keeping people connected to screens. Online platforms like Facebook provide us with 'free' platforms to connect and share with our friends, while mining and reselling our private data. Online games are designed to be addictive and this sells. Our devices become indispensable to us, woven into the fabric of our quotidian lives and the construction of our identity and social context, yet we do not really own those devices despite the illusion of having purchased them. Ongoing use of our devices requires payment of regular phone service subscriptions, data storage fees; an ongoing device function is only guaranteed through regular updating of software, and regular replacement with the latest models of expensive gadget.

\section{CONCLUSION}

The communication technology revolution of the $21^{\text {st }}$ century is profoundly reconfiguring the social world, including new social norms, and ways of being in the world. For people with disabilities, and more generally, we do not yet fully understand the social and other implications of the digital era. On the one hand, there are new possibilities for liberation of people with disabilities - we are all becoming low-tech cyborgs to the extent that it is no longer exceptional to rely on technology to carry out day-to-day activities of life. The online world provides opportunities, to connect with friends and communities, and have social presence and identities that are self-determined and transcendent of the marginalisation experienced in the embodied world. On the other hand, we are also becoming addicted and enslaved to technologies that are giving rise to serious physical and mental health epidemics.

Our technological dependence is encouraged by, and makes us susceptible to exploitation by, powerful economic interests that extract resources and personal data from us, in exchange for the right to communicate with others, receive services, 
and organise our lives. Arguably, the most vulnerable to this exploitation are those who are the most dependent on technologies. In a world over-saturated with digital technology, the time and freedom to disconnect from it, and to engage with other human beings face-to-face is ever more coveted and expensive. In this sense, technology, instead of reducing inequalities amongst vulnerable people, including people with disabilities, arguably increases it through technological exploitation, reaffirming old hierarchies and social barriers.

As new forms of social inclusion/exclusion emerge from the negotiation of the roles for the material, the logical, and the living in the constitution of restoring, normalizing, enhancing and reconfiguring cyborgs, the meaning of being (en)able(d) or disabled, included or excluded, patient or labourer, care-giver or knowledge collector, is still dynamic, mediated by languages and media, and dependent on contexts which, in the end, are provided by the other and how the other sees us. A post-humanist approach to disability is not about making "impaired humans" integer, nor about making "integer humans" more than human, but about keeping selves ethically connected with others (BUZATO, 2017) whether by virtual embodiment or embodied virtuality.

\section{REFERENCES}

BARAD, K. (2003) Posthumanist Performativity: Toward an Understanding of How Matter Comes to Matter. Signs: Journal of Women in Culture and Society, v.28, n.3, pp. 801-31.

BARNES, C., \& MERCER, G. J. (2001). Disability culture. IN: Handbook of disability studies. Thousand Oaks: SAGE Publications, pp. 515-34.

BEYOND BLUE. (2019). Beyond Blue Support Service. Retrieved from: https:/www. beyondblue.org.au/. Last accessed: 10 April 2019

BOWLES, N. (2019). Human Contact is Now a Luxury Good, The New York Times, 23 March. Retrieved from: https:/www.nytimes.com/2019/03/23/sunday-review/ human-contact-luxury-screens.html. Last accessed: 10 April 2019

BRAIDOTTI, R. (2016). Posthuman Critical Theory. In: Banerji, D.; Paranjape, M. (eds) Critical Postbumanism and Planetary Futures. Springer, New Delhi, pp. 13-32

BREWSTER, K. (2016). Digital detox: A family's struggle with technology addiction, ABC News, 13 September. Retrieved from: https://www.abc.net.au/news/2016-09-13/ 
digital-detox-family-struggles-with-technology-addiction/7836026 Last accessed: 10 April 2019

BROWN, V. (2016). The digital addiction that has teens wearing nappies so they don't need a toilet break. News.com.au, 8 June. Retrieved from: https://www.news. com.au/lifestyle/health/health-problems/the-digital-addiction-that-has-..--teenswearing-nappies-so-they-dont-need-a-toilet-break/news-story/5e0d321846a93337 dc9f0260fc0ffc23. Last accessed: 10 April 2019

BUZATO, M. E. K. (2017), Towards a theoretical mashup for studying posthuman/ postsocial ethics, Journal of Information, Communication and Ethics in Society, V. 15, no 01, pp. 74-89. https://doi.org/10.1108/JICES-06-2016-0021

CAMPBELL, F. (2009). Contours of ableism: The production of disability and abledness: London: Palgrave Macmillan Ed., 2009

CASE, A. (2010). What is a Cyborg? Retrieved from: <http://cyborganthropology.com/ What is a Cyborg\%3F>. Last accessed: 22 June 2019.

CHANG, Y.J., CHEN, S.F., \& HUANG, J.D. (2011). A Kinect-based system for physical rehabilitation: A pilot study for young adults with motor disabilities. Research in developmental disabilities, v.32, nº 6, pp. 2566-2570.

CLYNES, M. E., \& KLINE, N. (1960). Cyborgs and space, Astronautics, September: 26-7 and 74-5. Reprinted in Gray, Mentor, and Figueroa-Sarriera. 1995. IN: The cyborg bandbook. New York Routledge, pp. $29-34$.

COCO, A. P. (2010). Diseased, maimed, mutilated: categorizations of disability and an ugly law in late nineteenth-century chicago. journal of social history, v. $44, n^{\circ} 1$, pp. 23-37.

COOK, A. M., \& HUSSEY, S. M. (1995). Assistive technologies : principles and practice. St. Louis: Mosby Ed., 1995.

DEVLIN, A \& LAKE, E. (2018). What is a robot sex doll, how much do they cost and what is the sex robot brothel in Paris? The Sun Online - UK Editions, London. Retrieved from: < https://www.thesun.co.uk/tech/2084051/robot-sex-doll-sex-brothel-pariscost/>. Last accesseded: 19 jan. 2019.

EDYBURN, D. L. (2001). Critical issues in special education technology research: What do we know? What do we need to know? In: Technological Applications, v. 15, pp. 95-117. 
FOSTER, M. (2018). Aging Japan: Robots may have role in future of elder care. Reuters, US Edition. Retrieved from: < https://www.reuters.com/article/us-japan-ageingrobots-widerimage/aging-japan-robots-may-have-role-in-future-of-elder-careidUSKBN1H33AB > . Last accessed: 23 June 2019.

GOODWIN, C.; DURANTI, A. (1992). Rethinking Context: an Introduction. In: Duranti, A; Goodwin, C. (Org.). Rethinking context: language as an interactive phenomenon. Cambridge [England]; New York: Cambridge University Press, v. 11, pp. 1-42.

GOOSEY-TOLFREY, V., \& MINETTI, A. (2005). Biomechanics and energetics of basketball wheelchairs evolution. International journal of sports medicine, v. 26, $\mathrm{n}^{\mathrm{O}} 05$, pp. 388-396.

GRAY, C. H., FIGUEROA-SARRIERA, H. J., \& MENTOR, S. (1995). The cyborg bandbook.

GRIFFIN, G. (2017). A dictionary of gender studies. Oxford: Oxford University Press.

HALACY, D. S. (1965). Cyborg: Evolution of the superman. Harper \& Row.

HAMILTON, M. T., HAMILTON, D. G., \& ZDERIC, T. W. (2007). Role of low energy expenditure and sitting in obesity, metabolic syndrome, type 2 diabetes, and cardiovascular disease. Diabetes, v. 56, n 11 , pp. 2655-2667.

HAMPTON, K. N., SESSIONS, L. F., HER, E. J., \& RAINIE, L. (2009). Social isolation and new technology. Washington, DC: Pew Internet and American Life Project. Retrieved from https://pewrsr.ch/2KFty4T, Last accessed: 11 June 2019.

HAYLES,K. (1999). How we became posthuman: virtual bodies in cybernetics, literature, and informatics. Chicago, Ill: University of Chicago Press Ed., 1999.

HEETER, C. (2000). Interactivity in the Context of Designed Experiences. Journal of Interactive Advertising, v.1, $\mathrm{n}^{\circ} 1$, pp. 3-14.

HERR, H. (2018). How we'll become cyborgs and extend human potential. MIT Media Lab. Retrieved from: https://www.media.mit.edu/posts/hugh-herr-ted-2018/. Last accessed: 10 June 2019.

HESS, D. J. (1995). On low-tech cyborgs. In: The cyborg handbook, New York: Routledge, pp. 371-378.

HOLLOWAY, G. (1994). Susto and the career path of the victim of an industrial accident: a sociological case study. Social Science \& Medicine, v. 38, nº 7, 989-997. 
IRWIN, C. B., \& SESTO, M. E. (2012). Performance and touch characteristics of disabled and non-disabled participants during a reciprocal tapping task using touch screen technology. Applied ergonomics, v. 43, nº 6, pp. 1038-1043.

JAMES, P. (1996) Nation formation: Towards a theory of abstract community. London: Thousand Oaks. Ed., 1996

JAMES, P. (2014) 'Emotional Ambivalence across Times and Spaces: Mapping Petrarch's Intersecting Worlds', Exemplaria, v. 26 . n ${ }^{\circ}$, pp. 81-104.

JAMES, P. AND KATH, E. (2014) Siracusa. (2014). Global reconciliation: Responding to tension through a local-global process. London, United Kingdom: SAGE Publications. Ed., 2014.

JENKINS, R. (1998). Culture, classification and (in)competence. In: Questions of competence: Culture, classification and intellectual disability: Cambridge University Press., pp. 1

KIM, J., LAROSE, R., \& PENG, W. (2009). Loneliness as the cause and the effect of problematic Internet use: The relationship between Internet use and psychological well-being. CyberPsychology Behavior, v. 12, no 4, pp. 451-455.

MAHON, P. (2017). Posthumanism: A guide for the perplexed. Bloomsbury Publishing. Ed., 2017

MEYER, B., \& ASBROCK, F. (2018). Disabled or Cyborg? How Bionics Affect Stereotypes Toward People With Physical Disabilities. Frontiers in Psychology, v. 9, pp. 1-13

MILLER, V. (2012). A Crisis of Presence: On-line Culture and Being in the World. Space and Polity, v. $16, \mathrm{n}^{\circ} 3$, pp. 265-285.

MITRA, S. (2006). The Capability Approach and Disability. Journal of Disability Policy Studies, v. $16, \mathrm{n}^{\circ} 4$, pp. $236-247$.

MORE, M. (1990), Principles of Extropy, Version 3:11, 2003. Retrieved from: http://www. extropy.org/principles.htm. Last accessed: 22 June 2019.

MOSER, I. (2000). Against normalisation: subverting norms of ability and disability. Science as culture, v. 9, $n^{\circ} 2$, pp. 201-240.

MOSER, I. (2005). On becoming disabled and articulating alternatives: The multiple modes of ordering disability and their interferences. Cultural Studies, v. 19, $\mathrm{n}^{\circ}$ 6, pp. 667-700.

MOULIER-BOUTANG, Y. (2011). Cognitive capitalism. Cambridge, UK, Malden, MA: Polity Press, 2011. 
MUHAMMAD, N. M., SCHNEIDER, M., HILL, A., \& YAU, D. M. (2019). How the Use of iPad and Smartphones Creates Social Isolation. Proceedings of Society for Information Technology \& Teacher Education International Conference. Las Vegas, NV, United States: Association for the Advancement of Computing in Education (AACE), pp. 1060-1065.

NAYAR, P. K. a. (2014). Postbumanism. Cambridge: Polity Press. Ed., 2014.

OLIVER, M. B., COLIN. (2012). The new politics of disablement. Houndmills, Basingstoke, Hampshire New York, NY: Palgrave Macmillan. Ed., 2012.

PHILLIPS, T. (2017). Electronic heroin: China's boot camps get tough on internet addicts. The Guardian, 29 august. Retrieved from: https://www.theguardian.com/world/2017/ aug/28/electronic-heroin-china-boot-camps-internet-addicts. Last accessed: 22 June 2019

QUINLAN, M., \& BATES, B. (2009). Bionic Woman (2007): Gender, disability and cyborgs. Journal of Research in Special Educational Needs: JORSEN., v. 9, nº 1, pp. 48-58.

REEVE, D. (2012). Cyborgs, Cripples and iCrip: Reflections on the Contribution of Haraway to Disability Studies. In D. Goodley, B. Hughes, \& L. Davis (Eds.), Disability and Social Theory: New Developments and Directions. London: Palgrave Macmillan UK, pp. 91-111.

SCHAUBERT, V. (2019). My disabled's son amazing gaming life in the World of Warcraft. BBC, 07 feb. Retrieved from: https://www.bbc.com/news/disability-47064773. Last accessed: 22 June 2019

SHAKESPEARE, T. (2013). Disability rights and wrongs revisited: New York: Routledge. Ed., 2014.

SHARP, G. (1985). Constitutive abstraction and social practice. Arena, v. 70, 48-82.

SHARP, G. (1993). Extended forms of the social: technological mediation and selfformation. Arena Journal, v.1, pp. 221-237.

SINGH, M. (2019). Compulsive digital gaming: an emerging mental health disorder in children. The Indian Journal of Pediatrics, v. 86, $\mathrm{n}^{\mathrm{O}} 2$, pp. 171-173.

UN (2006). Convention on the rights of persons with disabilities and optional protocol. New York: United Nations. Retrieved from: https://www.un.org/development/desa/ 
disabilities/convention-on-the-rights-of-persons-with-disabilities.html. Last accessed: 22 June 2019

UPIAS (The Union of the Physically Impaired Against Segregation and The Disability Alliance discuss Fundamental Principles of Disability). Retrieved from: https://bit. ly/2wNSvD6. Last accessed: 11 June 2019.

WITTINK, H., ENGELBERT, R., TAKKEN, T. (2011). The Dangers of inactivity; exercise and inactivity physiology for the manual therapist. Manual therapy, v. 16, $\mathrm{n}^{\circ}$ 3, pp. 209-216.

WHO - World Health Organization (2018). 'Gaming disorder'. Retrieved from: https:// bit.ly/2GzsL5n: Last acessed: 4 June 2019.

Recebido: 29/05/2019

Aceito: 31/07/2019

Publicado: 2/08/2019 